NEWSLETTER

Valera Castanov, PhD'

Xiya Ma, MS $\boldsymbol{c}^{2}$

Adam Pietrobon, BSc ${ }^{3}$

Alan Blayney, $\mathrm{BSc}^{4}$

Alexander Levit, PhD'

Danielle Weber-Adrian, $\mathbf{P h D}{ }^{1}$

Nora Hutchinson, MD $^{6}$

Tina Binesh Marvasti, $\mathrm{MSc}^{7}$

Elina K Cook, MSc ${ }^{1}$

${ }^{1}$ School of Medicine, Queen's University,

Kingston, ON

2 Faculté de Médecine, Université de

Montréal, Montréal, QC

${ }^{3}$ Faculty of Medicine, University of Ottawa, ON

${ }^{4}$ Upstate Medical University, State University of New York, Syracuse, NY

${ }^{5}$ Schulich School of Medicine and Dentistry, Western University, London, ON

${ }^{6}$ Faculty of Medicine, McGill University, Montréal, QC

7 Faculty of Medicine, University of Toronto, Toronto, ON

Clin Invest Med 2019; 42 (3): E1-5.

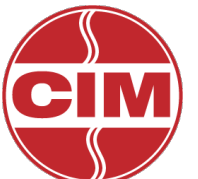

\section{Newsletter Fall 2019: \\ Clinician Investigator Trainee Association of Canada (CITAC)}

\section{A message from Elina Cook (President): Demystifying and promoting the MD-PhD/MSc world-our progress}

Clinician Investigator Trainee Association of Canada (CITAC) seeks to promote, support and advocate for trainees whose goal is to become physician/ clinician/surgeon investigators. These include trainees of $\mathrm{MD}-\mathrm{PhD} / \mathrm{MSc}$ programs and Clinician Investigator Programs (CIP), who are preparing themselves to succeed in the overlapping world of medicine and research. Thanks to the wealth of talent, skill and motivation of the CITAC leadership this year, we are delivering new opportunities to these trainees in a number of ways: 1) developing international partnerships and initiatives; 2) revitalizing the Annual General Meeting (AGM); 3) advocating for clinician/physician/surgeonscientist trainee support among influencers and policy makers; and 4) collecting data on the academic "health" of our training programs and trainees across Canada.

As President of CITAC, my mission this year has been to build on resources to help trainees on their own personal odysseys to becoming clinician scientists.

To access the fruits of our labour, continue reading here, stay tuned to CITAC's email announcements (e.g., on how to benefit from our pan-Canada mentorship program), and join us in Banff in November! Please do not hesitate to contact me at: president@citac-accfc.org

Correspondence to:

Xiya Ma

E-mail: xiya.ma@umontreal.ca 


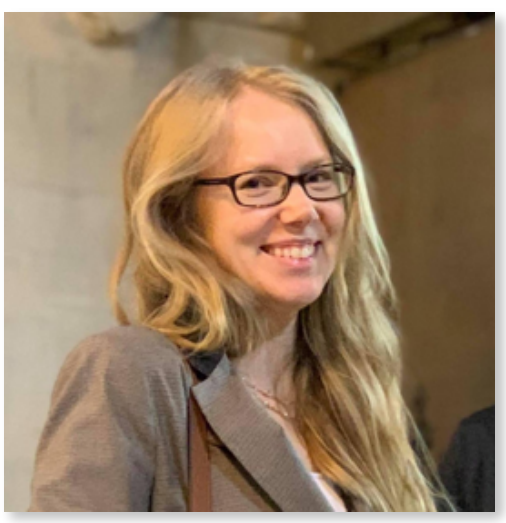

\section{A message from Elina Cook (President): Demystifying and promoting the MD-} $\mathrm{PhD} / \mathrm{MSc}$ world-our progress

Clinician Investigator Trainee Association of Canada (CITAC) seeks to promote, support and advocate for trainees whose goal is to become physician/clinician/surgeon investigators. These include trainees of $\mathrm{MD}-\mathrm{PhD} / \mathrm{MSc}$ programs and Clinician Investigator Programs (CIP), who are preparing themselves to succeed in the overlapping world of medicine and research. Thanks to the wealth of talent, skill and motivation of the CITAC leadership this year, we are delivering new opportunities to these trainees in a number of ways: 1) developing international partnerships and initiatives; 2) revitalizing the Annual General Meeting (AGM); 3) advocating for clinician/physician/surgeon-scientist trainee support among influencers and policy makers; and 4) collecting data on the academic "health" of our training programs and trainees across Canada.

As President of CITAC, my mission this year has been to build on resources to help trainees on their own personal odysseys to becoming clinician scientists.

To access the fruits of our labour, continue reading here, stay tuned to CITAC's email announcements (e.g., on how to benefit from our pan-Canada mentorship program), and join us in Banff in November! Please do not hesitate to contact me at: president@citac-accfc.org.

\section{CITAC leadership 2018-2019}

Elina Cook, MD/PhD student, Queen's University - President

Tina B. Marvasti, MD/PhD student, University of Toronto - President Elect

Alan Blayney, MD/PhD student, SUNY Upstate - CITAC VP External

Bahar Behrouzi, MD/PhD student, University of Toronto - CITAC VP External Elect

Xiya Ma, MD/MSc student, Université de Montréal - CITAC VP Internal

Valera Castanov, PhD MD student, Queen's University - CITAC VP Internal Elect

Melica Nourmoussavi, MD, CIP trainee, Université de Montréal - CITAC Secretary

Matthaeus Ware, MD/PhD student, University of Toronto - CITAC Treasurer

Adam Pietrobon, MD/PhD student, University of Ottawa - CITAC Policy Chair

Nora Hutchinson, MD, CIP trainee, McGill University - CITAC CIP Chair

Alexander Levit, MD/PhD student, Western University - CITAC PR Chair

Kevin Fan, MD/PhD student, University of British Columbia - CITAC Mentorship Chair

Sara Mirali, MD/PhD student, University of Toronto - CITAC Membership Chair

Julieta Lazarte, MD/PhD student, Western University - CITAC AGM Co-Chair

Danielle Weber-Adrian, PhD, MD student, Queen's University - CITAC AGM Co-Chair

Margaret Sun, PhD, MD student, Dalhousie University - CITAC CIM Liaison

Siddharth Nath, MD/PhD student, McMaster University - CITAC CFMS Liaison

Matthaeus Ware, MD/PhD student, University of Toronto - CITAC Finance Chair

Patrick Steadman, MD/PhD student, University of Toronto - CITAC Special Projects Chair 


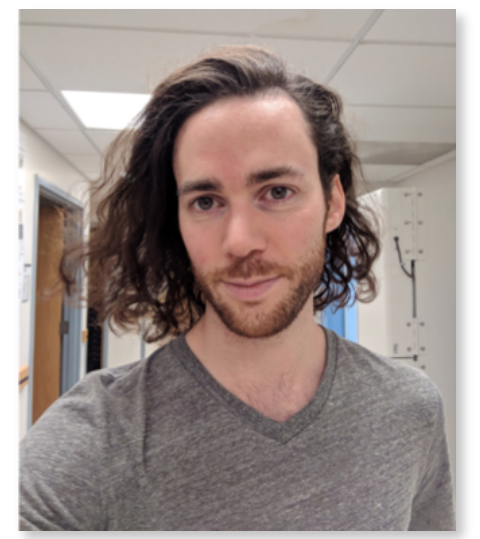

A message from Alan Blayney (VP External)

CITAC leadership have spent the past few years working to strengthen its ties to CITAC's American counterpart (American Physician Scientist Association, or APSA). This year, CITAC and our southern neighbours, along with partners across Europe and Asia, became founding members of the brand-new International Consortium of Clinician Scientist Trainee Organizations (ICCSTO). This will give CITAC members full access to events and resources, both physical and digital, from parallel organizations around the world. ICCSTO will also be holding annual meetings, hosted at partner organizations' own national events. The VP External team was in Paris for the first ICCSTO event this summer; the next will be held at the APSA AGM, April 3-5, 2020 in Chicago. Everyone's invited!

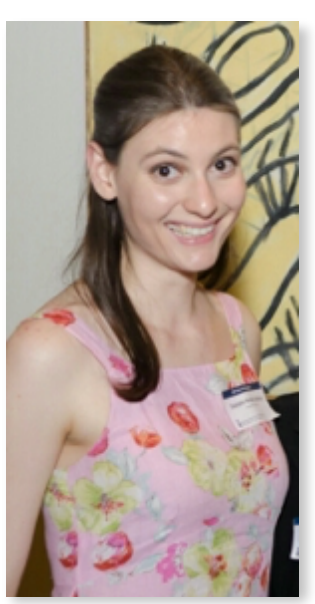

\section{A message from Danielle Weber-Adrian (AGM Co-Chair)}

In 2019, CITAC's AGM is headed west to Banff, Alberta, for November $8-10$, in an effort to broaden the networking opportunities of our attendees and to reach a different segment of the CITAC membership. The meeting will be taking place in the beautiful Banff Centre for Arts and Creativity, and will host a variety of keynote speakers and workshop topics surrounding our theme of "Positioning Early Career Investigators for Success: Strategy \& Resilience". Social and mentorship events are planned to foster communication and collaboration between attendees. Don't miss out! For more information visit our website at https://www.citacaccfc.org/, or email agm@citac-accfc.org with any questions.

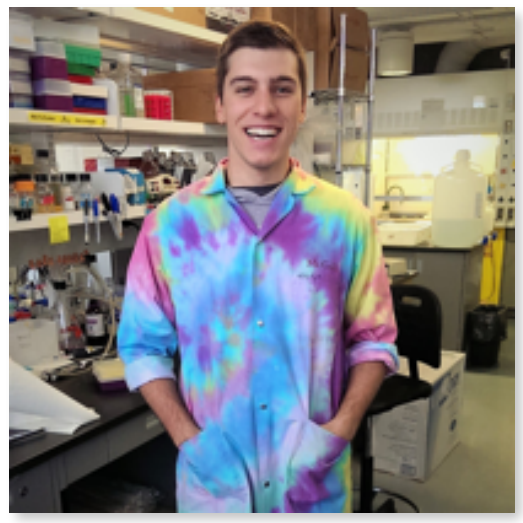

A message from Adam Pietrobon (Policy Chair)

CITAC's advocacy goals for this year were threefold: 1) to establish a 1 o ngitudinal relationship with key national organizations; 2) to advocate for the key recommendations stemming from the National Consensus Conference on Physician-Scientist training; and 3) to contribute to critical data collection efforts on physicianscientist trainees. Overall, we advocated for several critical actions: establishment of a national committee on physicianscientist training in Canada; bolstering funding sources for physician-scientist training; and improving continuity and integration of the physician-scientist training pathway. Thus far, we have met with representatives from the Canadian Institutes of Health Research (CIHR) to provide feedback on their overall strategic approach to health professional research training. In addition, we have met with leadership from the Association of Faculties of Medicine of Canada (AFMC) to encourage further incorporation of physicianscientist training as part of their lobby priorities. We are currently collaborating with the Canadian Society for Clinical Investigation (CSCI) and AFMC to identify tangible advocacy priorities for bolstering the physician-scientist training pathway. Finally, we have generated and distributed two data collection surveys. The first survey characterizes the impact of CIHR funding withdrawal on the operation of $\mathrm{MD} / \mathrm{PhD}$ programs nationwide. The second characterizes $\mathrm{MD} / \mathrm{PhD}$ post-graduate training considerations and establish member advocacy priorities to ensure fiduciary responsibility. 


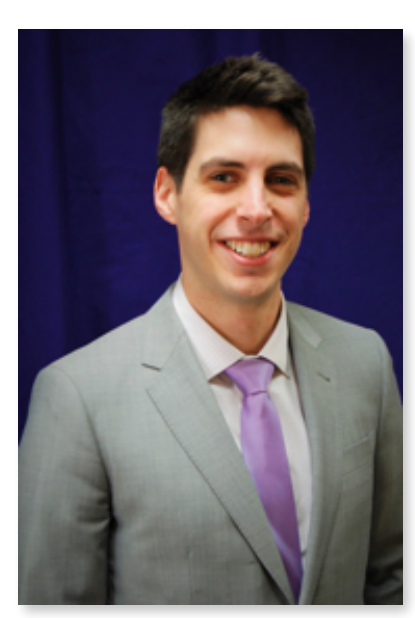

\section{A message from Alexander Levit (PR Chair)}

With the revival of CITAC's social media presence, we have seen great improvement in our social reach this past year. The Humans of CITAC series, which profiles MD+ and Clinical Investigator Program (CIP) trainees, has drawn much appeal and promises to bolster networking opportunities facilitated by CITAC. If you would like to submit your profile for the series, please contact citac@citac-accfc.org for more information.

We anticipate that our social media platforms will play a key role in promoting international outreach through ICCSTO. This collaboration further demonstrates the utility of social media in healthcare and research. For further insight into the role of social media in patient-physician relations, healthcare networks, research networks and education, we recommend the excellent review by Moorhead and coworkers (Moorhead SA et al. A new dimension of health care: Systematic review of the uses, benefits, and limitations of social media for health communication. J Med Internet Res. 2013;15(4):e85).

Be sure to follow us on Twitter \& Instagram@CITAC_ACCFC.

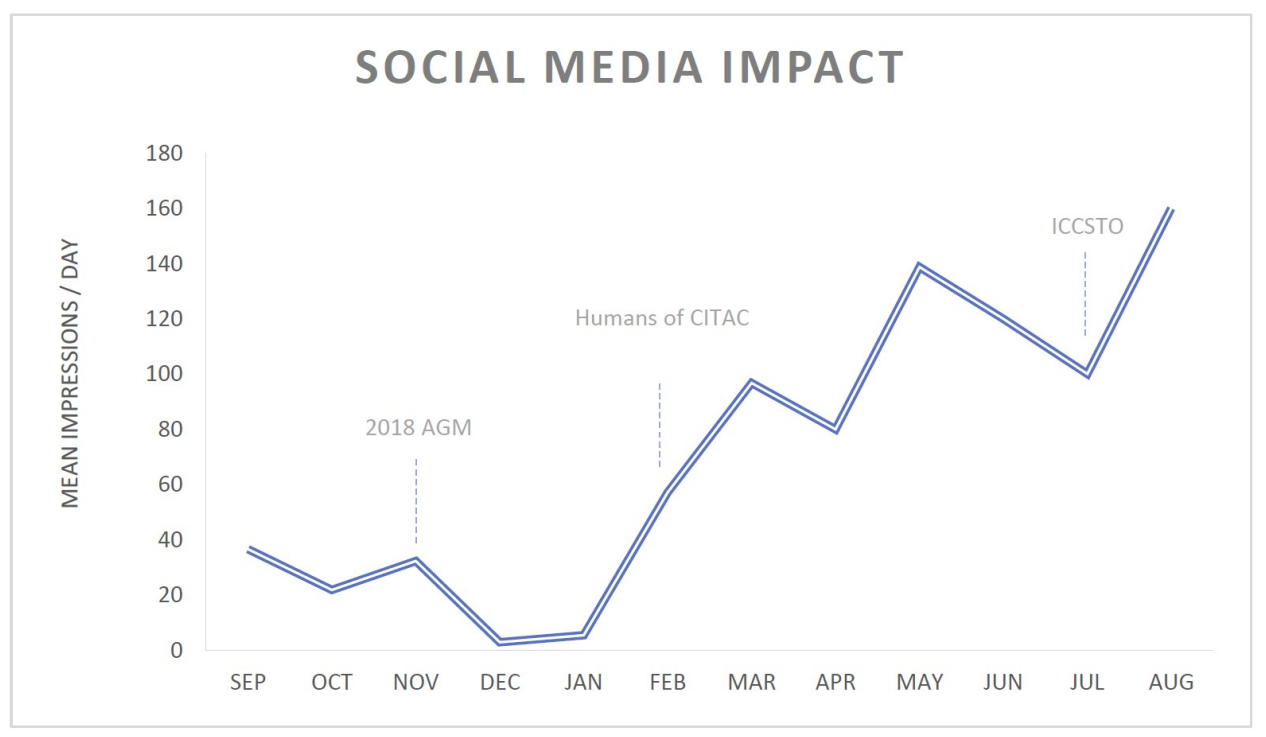

FIGURE 1. CITAC's social media impact has grown with new initiatives such as the Humans of CITAC series and ICCSTO.

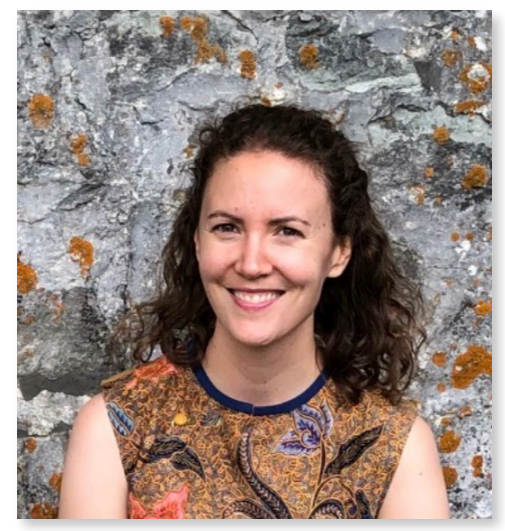

A message from Nora Hutchinson (CIP Chair)

A survey directed at CIP participants has been created and will be sent to all members in the fall. We aim to gain a better understanding of CIP members, their current stage of training and their research interests, and how CITAC can better serve CIP members in the future. We look forward to analysing these survey results and sharing them with the membership. In the meantime, if you have any ideas or comments on how CITAC can help improve CIP, please contact nora.hutchinson@mail.mcgill.ca. 


\section{A message from MD Financial Management}

How to conquer imposter syndrome in medical school and beyond

Dr. Nancy Yen Shipley, an orthopaedic surgeon and public speaker, has written that when she was in medical school, she was haunted by a voice in her head that would tell her, "They are going to find you out. You are a fraud." This kind of self-doubt, known as imposter syndrome, can stay with people long after they have finished their studies. Regardless of their many accomplishments, those with imposter syndrome feel they really aren't that bright — and somehow they've managed to fool those who think otherwise.

While imposter syndrome can affect professionals in just about any industry, those in medicine could be particularly susceptible to it, perhaps because the necessity to excel as a physician is literally seen as a matter of life and death.

\section{There are effective ways to counteract it}

Whether you're a medical student or practising physician suffering from imposter syndrome, you can mitigate its effects - but you have to work at it. As with learning any new skill, practice makes progress.

Remind yourself what you've done well. Spend less time worrying about being a fraud and more time appreciating yourself and acknowledging what your patients and other people appreciate about you.

Look through the eyes of others. Ask yourself how others would describe you - or ask them directly. What do you do well that others struggle with? What do people seek you out for advice on?

Talk to others. You will discover that many people around you feel the same way you do. You can also seek support from your professors (while you're still in training) and mentors (when you're new in practice).

Learn to reframe. If you really do slip up, try to reframe those failures as learning experiences that help with your professional development.

Interested in learning more about conquering imposter syndrome? Check out our full article here. https:// invested.mdm.ca/md-articles/how-to-conquer-impostersyndrome-in-medical-school-and-beyond.

Reprinted with permission of MD Financial Management 